\title{
Research on the Role of Professional Teachers in Overseas Practice of Teaching Chinese to Speakers of Other Languages: Taking Guilin University of Electronic Technology as an Example
}

\author{
Lin Zhang \\ College of Foreign Studies, Guilin University of Electronic Technology, Guilin, Guangxi, China
}

Keywords: Professional Teachers, Teaching Chinese.

\begin{abstract}
This paper discusses the guiding function of professional teachers in overseas teaching practice through survey of overseas practice situation of trainee in Teaching Chinese to Speakers of Other Languages of Guilin University of Electronic Technology. On this basis, some suggestions are put forward for overseas teaching practice guidance, this teaching and guiding activity with special significance.
\end{abstract}

\section{Introduction}

Overseas education practice is an important part and practice activity of undergraduate training of teaching Chinese to speakers of other languages, which combines the comprehensive practice link between characteristics of teaching Chinese to speakers of other languages and the training characteristics of normal school students. It is of great significance to ensure the training standards of the teachers of teaching Chinese to speakers of other languages. The guidance work of the professional teacher of teaching Chinese to speakers of other languages is an important guarantee to ensure the smooth progress of the practice activities in the overseas education practice [1].

This paper investigates 28 teachers who guide 2013 grade students in teaching Chinese to speakers of other languages of College of Foreign Languages of Guilin University of Electronic Technology, and tries to find out problems and analyze the causes of these problems [2-4].

\section{Survey of the guidance situation of overseas trainees by professional teachers}

The professional teachers' role is to inspire and guide the trainees in the overseas practice, and make trainees better adapt to the classroom. In the process of overseas teaching, teacher's guidance is mainly reflected in the pronunciation rectification, classroom skills, classroom management and other aspects, it also raises requirements for the overseas teaching practice of trainee, the trainees can apply the learned theoretical knowledge to the teaching practice, the influence of the teachers is very important.

We survey the 2013 grade trainees for the following aspects, and investigate several important aspects of the professional teachers for the practice guidance.

\subsection{Guidance before class}

There are 28 trainees in Vietnam practice, and they are divided into six groups, two groups of which are allocated to intermediate class, the other four groups are assigned to advanced class, each group is instructed by a Vietnamese teacher, and there are 6 teachers totally. There are five postgraduate students in the six teachers, four of which have one to two years of studying abroad experience, and Chinese teaching experience all has been over five years, another teacher is a doctor's degree, who has been studying in China for three years, and has rich experience in teaching Chinese.

We know that the guidance before class is usually guided by the teachers for teaching plan. One of the most experienced teachers, Su Wucheng, proposed that only writing good teaching plan can teach well. Therefore, every group meeting attaches most importance to teaching plan, and put forward the requirement that "start class after teaching plan passed". In the preparation for class stage, trainees 
will send own teaching plans in advance to the teachers by mail, then guide the teachers usually with phone, email and meetings and other ways to guide trainee.

It was found in the survey that $75 \%$ of the trainees thought it was difficult to prepare lessons. The reasons are: many new word, a large amount of PPT courseware, besides, the teaching process must be designed, the collection of related materials and so on. Because the vocabulary of the text is large, trainees often miss the point, therefore, words that teachers put forward in class must be close to the Chinese level of students without difficulty. The teachers mainly explain some classroom matters needing attention and class skills, for example: the guidance methods of the class are required to more close to life; the words to be explained should suit the students' Chinese level, the words and sentence-making to be explained are required to be written on the blackboard, if necessary, add the phonetic alphabet. Most of the teachers will carefully check the teaching plan of every trainee and correct the problems in it, for example, Hu Yuesheng use colored pens to mark the existing problems in teaching plan of trainee, and use words to elaborate, all the trainees in Mr. Hu's group thought Mr. Hu's guidance was the most serious

We understand that almost all teachers have put forward "concise teaching and many practice" principle: at least ten or twenty minutes should be reserved for students to speak and practice in one lesson. Not only that, practice should be varied, such as allowing students to express their views on the platform, go to the blackboard to do exercises, in short, it is necessary to take the learning initiative of students', take the initiative to speak and train more.

\subsection{Guidance after class}

The teachers ask the trainees to take won initiative actively in teaching practice. Guidance after class, every time after trainees finished one lesson, the teacher will organize group members to get together and review this lesson, after group members' comments each other, the teachers put forward own advice. Combining with interview contents, we understand teacher usually guide from trainee' manual speech, voice and other aspects, for example: During the teaching process, the trainees' voice should be loud, pronunciation should be clear, when explain the key words, there should be a clear tone and accent to attract the students' attention; even in the senior class, actually the students' Chinese level is not very high, so the trainees should also slow down the speaking speed and give students full understanding time, The key and difficult points in the text should not be too many, otherwise the students will have difficulty in digesting these knowledge, moreover, it is better to write on the blackboard when explaining vocabulary, pinyin and example sentences, and the blackboard-writing should be neat so that the students can see more clearly, and skillfully use various teaching methods, such as situational teaching method, example method, etc.

The teachers found that trainees lack skills for correcting students' mistakes in class, Vietnamese students' level tone is not long, aiming at this problem, the teachers put forward using gesture method and deliberately elongate to remind the students. After teachers' guidance, trainees infer other things from one fact in the subsequent classroom, falling tone of Vietnamese students does not lower, aiming at this problem, trainees intentionally elongate voice and use gesture to assist, properly slow down and open mouth, let the students observe their mouth.

We understand from the survey that $85 \%$ trainees think that the teachers provided a great deal of help to their teaching guidance. $75 \%$ trainees think group members are also very helpful in their teaching practice. Because group members adopt cooperation way, all are organized together to listen to the teachers and prepares lessons after class, so teaching advantages and disadvantages of everyone in the group are very clear, the problems that exist in the class of one group member will be discussed after class, remind each other, learn from each other, so everyone's teaching level has been improved, and effect is remarkable.

After the teachers' guidance, trainees learn to rethink their own problems, and make corresponding adjustments, for example: teachers rather than blindly on the platform, but properly walk beside students and communicate in class, which can ease the tension when the students answer the questions, and it is conducive to the development of teaching. After the practice of first lesson, with 
the help of the teachers and the group members, the trainees will handle the following course skillfully.

\subsection{Teacher's professional performance}

The trainees reflected that most of teachers were professional, especially the voice correction, such as correction of level tone and falling tone. Long (1996) proposed some strategies for correcting mistakes: it is best not to threaten students' face when corrected mistakes. The teachers can exercise the trainees' cooperation ability with the preparation method of group members' cooperation. After class, the teachers reorganized the group members to mutually make suggestions, found their advantages and disadvantages, and took the essence for use.

In the teaching aspect, the teachers proposed to be confident first, the sound in class should be bright and the blackboard-writing should be clear. The grammar formula can be listed when the key words are explained so that facilitates students' memory. Many trainees thought that writing is the most difficult lesson, because students are afraid to express them, and trainees lack the skills to guide students to speak as well. According to the interview, one teachers' writing course was very successful, the teacher first placed three photos of the characters to attract students' attention, made the students could imagine and make up a small story, explained description and narration methods of the characters smoothly, so as to achieve the purpose of classroom teaching. In this process, teachers use small gifts as rewards, and encourage students to raise their hands, and improve their participation and enthusiasm.

Survey found that when most of the trainees explained the new words, the method is too single, repetition method is generally used, let the students repeat, collectively read new words, the single teaching method is often difficult to achieve the teaching purpose. The teachers suggested that the explanation of new words should adopt more vivid teaching methods such as situational teaching methods. When explained "go shopping" lecture, trainees can organize students to perform on the platform in the classroom, and use the new words in the text to arrange students' dialogues. In this way, students' enthusiasms which participate in the classroom are improved and achieve the ultimate goal of Chinese learning, namely students can use Chinese knowledge in life. Trainees are more flexibly use teaching methods after teachers' guidance, and can be more proficient in the classroom teaching.

Many trainees reflect that teachers are patient and modest in guidance, and most Vietnamese teachers have about five years of teaching experience, who are very clear about the knowledge level and learning methods of Vietnamese students, so they can start from the reality of the Vietnamese students, calmly deal with the problem in the classroom. This is the best point for trainees to learn.

\section{Suggestions on the guidance work of overseas practice teachers}

Overseas practice teaching is a practice activity with heavy task, long time and relative complexity, through the survey of students, we think that the overseas practice teachers must strengthen practice guidance from the following several aspects:

(1) Insist on attending a lecture in each practice spot, each student attended a lecture at least, do guidance in class and the review work after class;

(2) Organize each practice group to conduct teaching research, guide the students to revise the teaching plan, and adjust the teaching method according to the actual situation;

(3) Communicate with trainees timely so that trainees can find out and solve problems that exist in teaching process and improve their teaching ability;

(4) Urge trainees to listen to each other, review lectures, reflect their own teaching problems, and learn from others' strong points and close the gap;

(5) Students who have outstanding problems in teaching should be coached emphatically;

(6) Enhance the education of students' psychological adaptive ability, and guide the students to gradually adapt to the environment of classroom teaching; 
(7) Pay attention to the practice school, especially the characteristics of the teaching object of the practice school, and guide students how to manage classroom teaching.

\section{Conclusion}

Overseas practice teaching is special and important link in Chinese international education personnel training, the teachers' guidance are right, which is conducive to improve students' Chinese teaching skills, finally achieve the purpose of professional personnel training. Overseas practice teachers, whether Chinese teachers or foreign teachers should be with responsible attitude, earnestly fulfill their duties, as well as to cultivate qualified Chinese teachers abroad, and make great efforts to train qualified overseas Chinese teachers.

\section{Acknowledgements}

This research was financially supported by the Project of Undergraduate Teaching Reform of Higher Education in Guangxi in 2015, in which the content was Research of Practice of Overseas Chinese Education based on Training System Integration in International Chinese Education Specialty (Grant No. 2015JGB225).

\section{References}

[1] Long. M. 1996. The Role of the linguistic Environment in Second Language Acquisition.in W. and T. Handbook of Second Language Acquisition. San Diego: Academic Press, 1996, 413.

[2] Wang Di. Comparative Research on Classroom Teaching Behavior Between Newcomer Teachers and Expert Teachers in Foreign Chinese[D], Beijing Foreign Studies University. 2014, $12,150-152$.

[3] Wang Picheng. Training of Teachers' Self-improvement ability in Teachers Trainings of International Education of Chinese Language[A], Beijing Normal University, 2005, 5 (45), 105-106.

[4] Wu Huaicheng. Discussion on the Practice Problems of Teaching Chinese to Speakers of Other Languages Undergraduates[J], Journal of Language and Literature Studies, 2016, (5), 31-33. 